\title{
Retrieval of a bread bag clip from the duodenum
}

A 73-year-old woman presented with iron deficiency anemia and melena. Biochemical parameters revealed a hemoglobin of $77 \mathrm{~g} / \mathrm{L}$ and urea $8.5 \mathrm{mmol} / \mathrm{L}$ with normal renal indices. She was transfused with 2 units of red blood cells. Gastroscopy revealed a bread clip embedded in D1 (showing the date Friday, 13 April - Fig. 1), pinching the distal and proximal duodenal roof fold and dangling like an earring. Attempts to remove the clip by crushing with grasping forceps, cutting with a needle-knife device, and snapping with snare were unsuccessful. A gastric band cutter (Endotherapeutics, Sydney, Australia) was employed endoscopically. The cutting wire was threaded between the bread clip and the duodenum ( Fig.2), and the free end was retrieved and locked into the racheting device, forming a loop. Tightening of the loop resulted in the wire snapping the clip, which was then retrieved orally (๑ Fig. 3).

Only 21 cases of bread clip ingestion have been reported since 1975. Most cases present as small-bowel perforation requiring bowel resection [1]. Bread clips are made of plastic and are therefore nondegradable. With an aging population, we postulate that such cases will be increasingly seen [2]. The shape of the clip results in a traplike effect, which prevents easy removal once it is embedded [3]. Endoscopic removal of embedded foreign bodies can require taking a unique approach. This is the first reported case of the use of a gastric band cutter to divide an embedded foreign body followed by successful retrieval.

Endoscopy_UCTN_Code_TTT_1AO_2AL

Competing interests: None

\section{N. S. Ding, A. Y. Ting, D. Loh, M. Leong, C. Hair}

Gastroenterology Unit, Geelong Hospital, Geelong, Australia

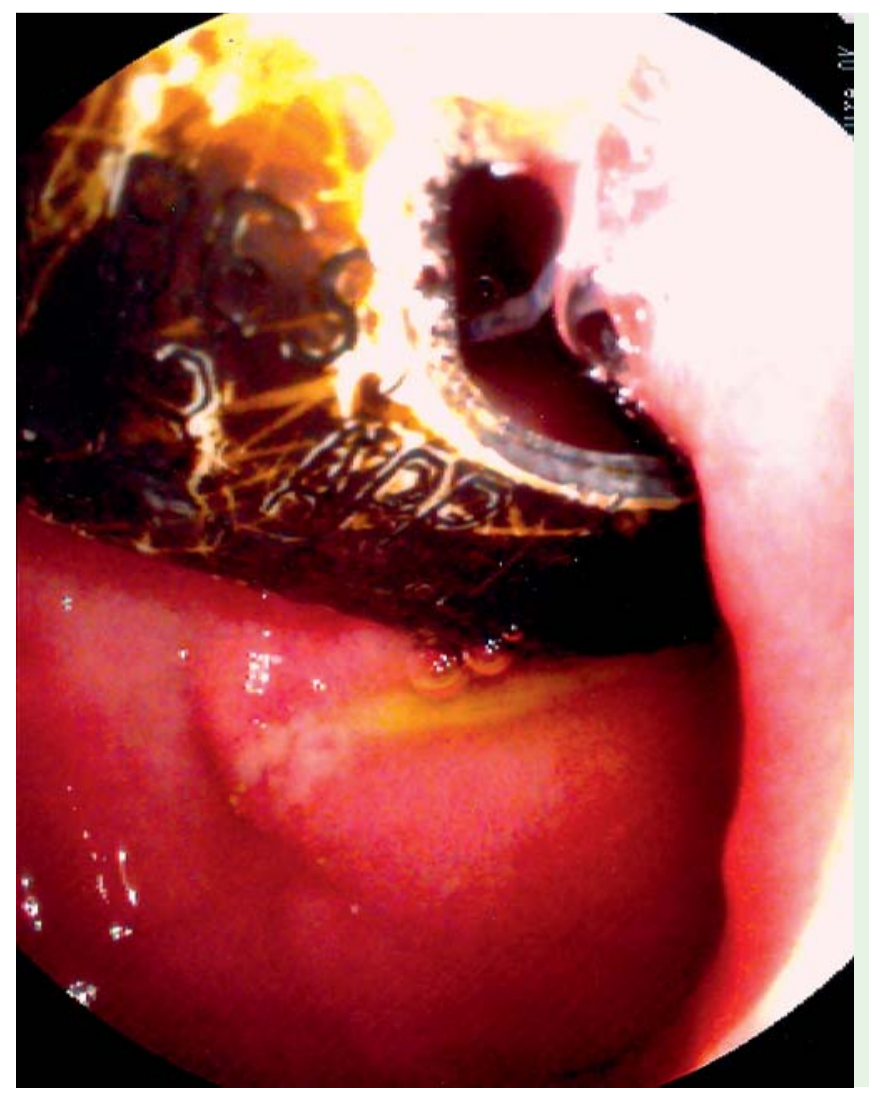

Fig. 1 Bread clip embedded in first part of duodenum in a 73-year-old woman presented with iron deficiency anemia and melena. There is linear erosion on the posterior wall.

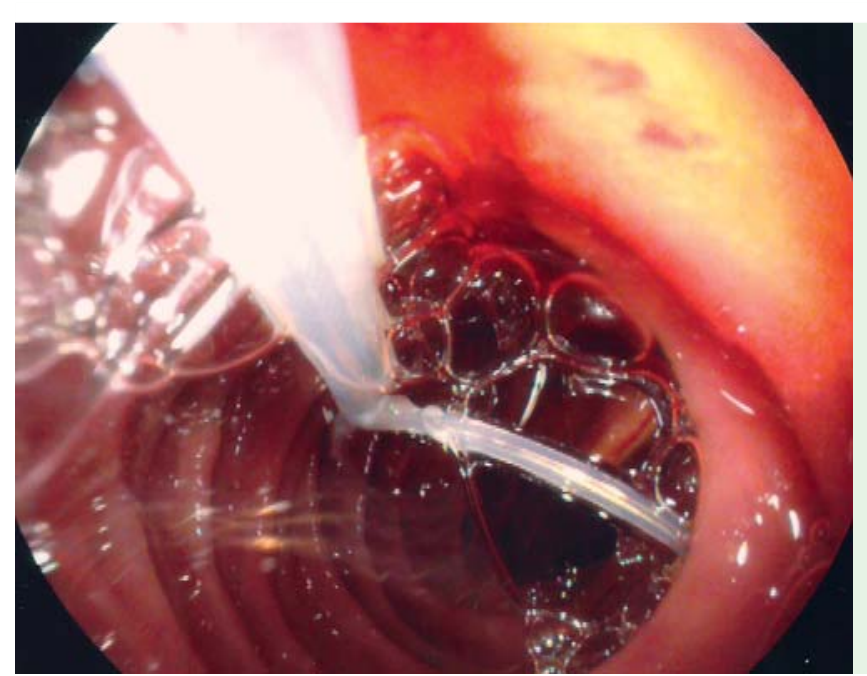

Fig. 2 The cutting wire was fed down the duodenum. 


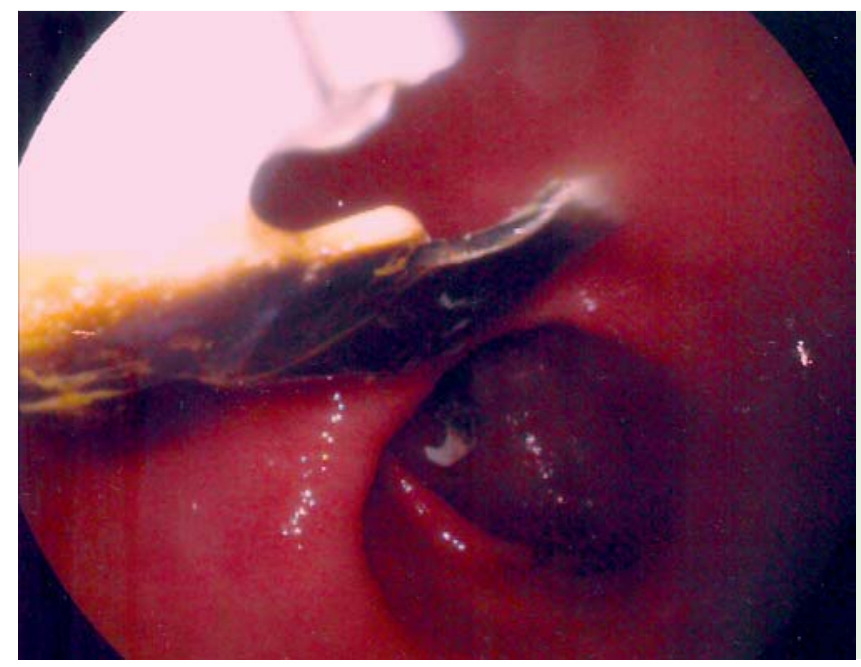

Fig. 3 The bread clip was divided and then retrieved orally.

\section{References}

1 Newell KJ, Taylor B, Walton JC et al. Plastic bread-bag clips in the gastrointestinal tract: report of 5 cases and review of the literature. CMAJ 2000; 162: 527-529

2 Beer T. Fatalities from bread tag ingestion. Med J Aust 2002; 176: 506

3 Tang A, Kong A, Walsh $D$ et al. Small bowel perforation due to a plastic bread bag clip: The case for clip redesign. ANZ J Surg 2005; 75: $360-362$

\section{Bibliography}

Dol http://dx.doi.org/

10.1055/s-0032-1325975

Endoscopy 2013; 45: E309-E310

(c) Georg Thieme Verlag KG

Stuttgart · New York

ISSN 0013-726X

\section{Corresponding author}

\section{N. S. Ding}

Gastroenterology Unit

Geelong Hospital

Geelong

Australia

dingnik@gmail.com 